\title{
Factors that modify the effect of excess calcium on skeletal development in puppies
}

\author{
Britta Dobenecker* \\ Chair of Animal Nutrition and Dietetics, Ludwig Maximilians University Munich, Schönleutnerstrasse 8, D-85764 \\ Oberschleißheim, Germany
}

(Received 15 October 2010 - Revised 5 April 2011 - Accepted 3 May 2011)

\begin{abstract}
Developmental skeletal problems are often connected to mistakes in feeding, i.e. a deficiency or excess supply of nutrients, especially minerals. The energy consumption, the resulting growth intensity and the breed of animals are also known as factors that influence developmental orthopaedic diseases. In most clinical trials, excess Ca was connected to alterations in normal, healthy skeletal development, which led to severe clinical symptoms in some dogs, subclinical changes in the radiographic or histological examinations in other animals, or even no observable symptoms. These results correspond to practical experience in the field of clinical nutrition consultation, since excess $\mathrm{Ca}$ has been shown to have various impacts in growing dogs. The present review of results published in the literature and from my own trials led to the hypothesis that $\mathrm{P}$ is an important co-factor that can alleviate or aggravate the development of skeletal problems in growing dogs.
\end{abstract}

Key words: Dogs: Growth: Calcium: Phosphorus

Excess $\mathrm{Ca}$ is considered detrimental to the growing skeletons of $\operatorname{dogs}{ }^{(1)}$. Practical experience in nutrition consultation shows that not all dogs under Ca excess develop skeletal problems. The same is true for own research work where the effects of feeding diets with excess Ca to growing dogs were not identical in all individuals ${ }^{(2)}$. The present review was undertaken to identify co-factors that alleviate or aggravate the effect of excess $\mathrm{Ca}$ on developmental orthopaedic diseases (DOD). Therefore, a literature review was performed to investigate the effects of excess $\mathrm{Ca}$ in growing dogs ${ }^{(1-14)}$. The parameters of special interest were the $\mathrm{Ca}$ and $\mathrm{P}$ intakes, Ca:P ratio, clinical and subclinical symptoms of DOD, breed, age and plasma $\mathrm{P}$ concentration, if available.

\section{Literature review and discussion}

In 1931, Marek \& Wellmann published their historical data on the effects of $\mathrm{Ca}$ and $\mathrm{P}$ supply in growing dogs. They summarised their findings about the detrimental effects of excess $\mathrm{Ca}$, concluding that the symptoms such as lameness or deviation of limb axes were more detrimental when the $\mathrm{P}$ content in the diet was not increased concurrently. It has been reported that two German Shepherd puppies developed severe clinical signs of skeletal problems, confirmed by radiological and histological findings, as well as hypophosphataemia after being fed excess $\mathrm{Ca}$ and a normal amount of P (calculated: 2.2\% $\left.\mathrm{Ca} ; 0.9 \% \mathrm{P}^{(10)}\right)$. Severe clinical signs of DOD were observed in a Fox Terrier puppy after adding $\mathrm{CaCO}_{3}$ to its diet, and these signs disappeared after $\mathrm{CaCO}_{3}$ was exchanged with bone meal, which led to an increase in the $\mathrm{P}$ supply and a balanced $\mathrm{Ca}: \mathrm{P}$ ratio. The underlying reason for these clinical signs might be the decreased availability of $\mathrm{P}$ in cases with a wide Ca:P ratio caused by a high $\mathrm{Ca}$ content of the diet, as described previously ${ }^{(15)}$. This effect of selective Ca excess on the apparent digestibility of $\mathrm{P}$ was also observed in Beagles during the own experiments ${ }^{(16)}$. The results of Nap et al. ${ }^{(11)}$ can help explain the sometimes inconsistent findings published more recently by various laboratories (Table 1 ).

Hazewinkel and his colleagues ${ }^{(4-7,12)}$ also observed detrimental effects in Great Danes (GD) after feeding the animals excess $\mathrm{Ca}$ in a diet with a $\mathrm{P}$ supply that fulfilled the minimum requirements $(0.9 \% \mathrm{DM} \text {; wide } \mathrm{Ca}: \mathrm{P} \text { ratio })^{(17)}$. In some studies of Fox Terrier, German Shepherd, and GD puppies fed an excess amount of $\mathrm{Ca}$, clinically severe symptoms were observed $^{(5,7,10,12)}$. In other studies, mild symptoms have been reported in puppies fed excess $\mathrm{Ca}$, and only subclinical effects were measured in radiographs or through histology ${ }^{(3)}$, or no symptoms have been observed or reported ${ }^{(6,14)}$. In another trial using Miniature Poodles (MP), the combination of excess $\mathrm{Ca}$ and a marginal $\mathrm{P}$ supply did not cause signs of

Abbreviations: DOD, developmental orthopaedic diseases; GD, Great Danes; MP, Miniature Poodles.

*Corresponding author: B. Dobenecker, fax +49 89 218078702. email dobenecker@lmu.de 
Table 1. Effects of excess calcium on growing dogs

\begin{tabular}{|c|c|c|c|c|c|c|c|c|c|}
\hline Author and year & Breed & $\mathrm{Ca}(\% \mathrm{DM})$ & $\mathrm{P}(\% \mathrm{DM})$ & Age (week) & $\begin{array}{l}\text { Number } \\
\text { of dogs }\end{array}$ & $\begin{array}{l}\text { Effect (X-rays } \\
\text { or histology) }\end{array}$ & \multicolumn{2}{|c|}{ Clinical symptoms } & Feed intake \\
\hline \multirow[t]{2}{*}{ Hazewinkel et al. $(1991)^{(7)}$} & Great Dane & 3.3 & 0.9 & $5(10)-(11) 26$ & 6 & n.m. & \multicolumn{2}{|l|}{ Yes $^{*}$} & Reduced (week 14) \\
\hline & Great Dane & $3 \cdot 3$ & 3 & $5(10)-(11) 26$ & 6 & n.m. & \multicolumn{2}{|l|}{ n.m. } & Normal \\
\hline Hazewinkel et al. $(1985)^{(5)}$ & Great Dane & $3 \cdot 3$ & 0.9 & $5(10)-25$ & 6 & Yes & \multicolumn{2}{|l|}{ Yes } & Reduced \\
\hline Hazewinkel et al. (1987)(6) & Great Dane & $3 \cdot 3$ & 0.9 & $5(10)-25$ & 6 & Yes & \multicolumn{2}{|l|}{ n.m. } & Reduced \\
\hline $\begin{array}{l}\text { Voorhout \& Hazewinkel } \\
(1987)^{(14)}\end{array}$ & Great Dane & $3 \cdot 3$ & 0.9 & $7-21$ & 6 & Yes & \multicolumn{2}{|l|}{ No } & n.m. \\
\hline $\begin{array}{l}\text { Goedegebuure \& Hazewinkel } \\
(1986)^{(3)}\end{array}$ & Great Dane & $3 \cdot 3$ & 0.9 & $6-26$ & 6 & Yes & Yes & $\begin{array}{l}\text { Bulging of osteochondral } \\
\text { junction ribs }\end{array}$ & n.m. \\
\hline \multirow[t]{2}{*}{ Schoenmakers et al. $(2000)^{(12)}$} & Great Dane & $3 \cdot 1$ & 0.9 & $6-27$ & 9 & Yes & \multicolumn{2}{|c|}{ Yes } & n.m. \\
\hline & Great Dane & $3 \cdot 1$ & $2 \cdot 8$ & $6-27$ & 6 & (Yes) not severe & (Yes) & Not severe & n.m. \\
\hline Lauten et al. (2002) $)^{(8)}$ & Great Dane & $2 \cdot 7$ & $2 \cdot 2$ & $5-24$ & 32 & No & & Normal \\
\hline Goodman et al. $(1998)^{(4)}$ & Great Dane & $2 \cdot 7$ & $2 \cdot 2$ & $5-24$ & 13 & yes & \multicolumn{2}{|l|}{$\begin{array}{l}\text { No } \\
\text { (Yes) }\end{array}$} & n.m. \\
\hline Lepine $(1998)^{(9)}$ & Great Dane & $2 \cdot 7$ & $2 \cdot 2$ & $6-72$ & 15 & Yes & Yes & $\begin{array}{l}\text { Six out of fifteen pups transient } \\
\text { lameness. Three out of } \\
\text { fifteen HOD }\end{array}$ & n.m. \\
\hline Nap et al. (1993) ${ }^{(11)}$ & Miniature Poodle & $3 \cdot 3$ & 0.9 & $6-18$ & 21 & n.e. & No & & Reduced (week 11) \\
\hline Stephens et al. (1985) ${ }^{(13)}$ & Beagle & $2.8-3.9 \dagger$ & $1 \cdot 1$ & $7-17$ & 9 & Yes & No & & n.m. \\
\hline Marek \& Wellmann (1931) ${ }^{(10)}$ & Small Mongrel & $2 \cdot 2$ & 0.9 & $6-18$ & 6 & Yes & Yesł & & Normal \\
\hline \multirow[t]{2}{*}{ Dobenecker et al. (2006) ${ }^{(2)}$} & Foxhound crossbred & 3.6 & 1.25 & $6-27$ & 35 & No & \multicolumn{2}{|l|}{ No } & Normal \\
\hline & Beagle & 3.6 & 1.25 & $6-27$ & 25 & Yes & \multicolumn{2}{|l|}{ No } & Normal \\
\hline \multirow[t]{2}{*}{$\begin{array}{l}\text { Dobenecker \& Kienzle } \\
(2008)^{(19)} \S\end{array}$} & Foxhound crossbred & 1.2 & 0.35 & $6-12(14)$ & 19 & n.e. & Yes & $\begin{array}{l}\text { (Four out of nineteen } \\
\text { bowed legs) }\end{array}$ & Reduced \\
\hline & Beagle & $1 \cdot 2$ & 0.35 & $6-12(14)$ & 15 & n.e. & Yes & $\begin{array}{l}\text { (Three out of fifteen } \\
\text { bowed legs) }\end{array}$ & Reduced \\
\hline
\end{tabular}

n.e., not examined; n.m., not mentioned.

* In one sentence, severe skeletal abnormalities were mentioned.

† Constant supplementation of $2.3 \mathrm{~g} \mathrm{Ca} / \mathrm{d}$ per dog.

$¥$ Clinical symptoms disappeared when one of the dogs received $\mathrm{P}$ in addition to excess $\mathrm{Ca}$.

$\S$ Supply with low $\mathrm{P}$ and normal Ca for comparison. 
DOD $^{(11)}$. Therefore, excess Ca alone without a concomitant increase in the $\mathrm{P}$ supply (i.e. a wide Ca:P ratio $>2 / 1$ ) seems to trigger signs of DOD in growing dogs of certain breeds, especially GD, and increase the number of severely affected puppies. In dogs with severe clinical symptoms, some authors have reported hypophosphataemia ${ }^{(7,10)}$, which supported the hypothesis that $\mathrm{P}$ deficiency is a major co-factor in the development of skeletal problems in puppies fed excess $\mathrm{Ca}$. Accordingly, trials were performed where $\mathrm{P}$ levels were elevated approximately $25 \%$ or more above the minimum requirements or were provided at $0.9 \%$ of the DM to ensure a more balanced Ca:P ratio. These trials led to less severe skeletal changes or, more frequently, to no clinical symptoms at all $\left(\mathrm{GD}^{(4,7,9,12)}\right.$; Beagles $\left.{ }^{(2,13)}\right)$. When Foxhound crossbreeds were fed a P supply above the previously published recommended allowance ${ }^{(18)}$, the animals developed no clinical or subclinical symptoms ${ }^{(2)}$. Lauten et al. did not state their clinical findings clearly enough to evaluate their results in this context ${ }^{(8)}$.

The hypothesis that DOD in growing dogs is related to the co-factor P supply was reinforced by the results of a study of $P$ deficiency in growing Beagles and Foxhound crossbreeds ${ }^{(19)}$. The puppies received a diet providing approximately $40-50 \%$ of the recommended $\mathrm{P}$ allowance (approximately $0.35 \%$ $\mathrm{DM}^{(18)}$ ) while the Ca supply met the requirements, resulting in a $\mathrm{Ca}: \mathrm{P}$ ratio above the recommended ratio. In this trial, some puppies of both breeds developed severe clinical symptoms of DOD.

Along with evaluating the impact of the nutrient supply, especially the supply of $\mathrm{Ca}$ and $\mathrm{P}$, it is important to consider other factors in the study of complex nutritionally triggered DOD. The adult body weight alone might influence the effects of excess Ca through body-weight development or the growth rate, which involves the corresponding hormonal status of the animal. Another potential factor is the susceptibility or sensitivity of the breed to certain nutritional factors. From the literature and from clinical experience, we know that large or giant dog breeds are more likely to develop skeletal problems during growth when they ingest insufficient or excess nutrients. Overall, dogs with an adult body weight of about $30 \mathrm{~kg}$ or more are more vulnerable to excess Ca. However, too intensive growth alone can lead to a greater frequency of developmental skeletal disease even when all nutrients are supplied according to the requirements ${ }^{(20)}$. The breeding of some dog varieties seems to be problematic even when the required energy and nutrient supplies are met. For example, in radiographic examinations ${ }^{(21)}$, there were diagnosed skeletal changes in GD but not in MP after feeding the animals a balanced diet without an excess of $\mathrm{Ca}$. The authors have reported that the majority of the GD showed abnormally flattened distal ulnar metaphyses with increasing incidence of cartilage cones, and the growth plates were more irregular in the GD than in the MP puppies.

The evidence collected in the present review supports the hypothesis that excess $\mathrm{Ca}$ is much more hazardous to growing dogs when it is accompanied by a low or a marginal $\mathrm{P}$ supply. Moreover, large and giant dogs are particularly prone to nutritionally triggered developmental skeletal diseases.

\section{Acknowledgements}

The present study received no specific grant from any funding agency in the public, commercial or non-profit sectors. No conflicts of interest exist.

\section{References}

1. NRC (2006) National Research Council. The Nutrient Requirements of Dogs and Cats. Washington, D.C.: The National Academic Press.

2. Dobenecker B, Kasbeitzer N, Flinspach S, et al. (2006) Calcium excess causes sub-clinical changes of bone growth in Beagles but not in Foxhound-crossbred dogs, as measured in X-rays. J Anim Physiol Anim Nutr 90, 394-401.

3. Goedegebuure SA \& Hazewinkel HAW (1986) Morphological findings in young dogs chronically fed a diet containing excess calcium. Vet Pathol 23, 594-605.

4. Goodman SA, Montgomery RA, Titch RB, et al. (1998) Serial orthopaedic examinations of growing Great Dane puppies fed three diets varying in calcium and phosphorus. In Recent Advances in Canine and Feline Nutrition, Iams Nutrition Symposium Proceedings, pp. 63-70 [GA Reinhart and DP Carey, editors]. Wilmington, NC: Orange Frazer Press.

5. Hazewinkel HAW, Goedegebuure SA, Poulos PW, et al. (1985) Influences of chronic calcium excess on the skeletal development of growing Great Danes. J Am Anim Hops Assoc 135, 305-310.

6. Hazewinkel HAW, Hackeng WHL, Bosch R, et al. (1987) Influences of different calcium intakes on calciotropic hormones and skeletal development in young growing-dogs. Front Horm Res 17, 221-232.

7. Hazewinkel HAW, Brom WE \& Van't Kloster A (1991) Calcium metabolism in Great Dane dogs fed diets with various calcium and phosphorus levels. J Nutr 121, S99-106.

8. Lauten SD, Cox NR, Brawner WR, et al. (2002) Influence of dietary calcium and phosphorus content in a fixed ratio on growth and development in Great Danes. A J Vet Res 63, $1036-1047$

9. Lepine AJ (1998) Nutritional influences on skeletal growth of the large breed puppy. In Proceedings of the North American Veterinary Conference, pp. 16-19.

10. Marek J \& Wellmann O (1931) Die Rhachitis - Pathologischer Teil. Jena, Germany: Gustav Fischer Verlag.

11. Nap RC, Hazewinkel HAW \& van den Brom WE (1993) 45Ca kinetics in growing miniature poodles challenged by four different dietary levels of Ca. J Nutr 123, 1826-1833.

12. Schoenmakers I, Hazewinkel HAW, Voorhout G, et al. (2000) Effects of diets with different calcium and phosphorus contents on the skeletal development and blood chemistry of growing Great Danes. Vet Rec 147, 652-660.

13. Stephens LC, Norrdin RW \& Benjamin SA (1985) Effects of calcium supplement and sunlight exposure on growing beagle dog. Am J Vet Res 46, 2037-2042.

14. Voorhout G \& Hazewinkel HAW (1987) A radiographic study on the development of the antebrachium in Great Dane pups on different calcium intakes. Vet Radiol 28, 152-157.

15. Jenkins K \& Phillips P (1960) The mineral requirement of the dog. 2. The relation of calcium, phosphorus and fat levels to minimal calcium and phosphorus requirements. J Nutr $\mathbf{7 0}$, 241-246. 
16. Dobenecker B (2002) Influence of calcium and phosphorus intake on the apparent digestibility of these minerals in growing dogs. J Nutr 132, 1665S-1667S.

17. NRC (1974) National Research Council. The nutrient requirements of dogs and cats. Washington, D.C.: The National Academic Press.

18. Meyer H \& Zentek J (2001) Ernährung des Hundes. Stuttgart, Germany: Ulmer Verlag.

19. Dobenecker B \& Kienzle E (2008) Normal calcium and low phosphorus intake in puppies leads to extremely bowed legs which are reversible by phosphorus repletion. In ESVCN Congress Proceedings, Vienna, pp. 26.

20. Zentek J, Meyer H, Daemmrich K, et al. (1995) Development of body-mass and skeleton in growing Great-Danes, as affected by energy supply. 3. Clinical-features and chemical skeletal analyses. J Vet Med 42, 69-80.

21. Tryfonidou MA, Holl MS, Vastenburg M, et al. (2003) Hormonal regulation of calcium homeostasis in two breeds of dogs during growth at different rates. J Anim Sci $\mathbf{8 1}$ 1568-1580. 